\title{
Contrasting impacts of pollen and seed dispersal on spatial genetic structure in the bird-pollinated Banksia hookeriana
}

\author{
SL Krauss ${ }^{1,2}$, T He ${ }^{1,3}$, LG Barrett ${ }^{3,4}$, BB Lamont ${ }^{3}$, NJ Enright ${ }^{3,5}$, BP Miller ${ }^{1,2,3}$ and ME Hanley ${ }^{3,6}$ \\ ${ }^{1}$ Botanic Gardens and Parks Authority, Kings Park and Botanic Garden, Perth, Western Australia, Australia; ${ }^{2}$ School of Plant Biology, \\ The University of Western Australia, Nedlands, Western Australia, Australia; ${ }^{3}$ Department of Environmental Biology, Centre for \\ Ecosystem Diversity and Dynamics, Curtin University of Technology, Perth, Western Australia, Australia; ${ }^{4}$ Department of Ecology and \\ Evolution, University of Chicago, Chicago, IL, USA; ${ }^{5}$ School of Environmental Science, Murdoch University, Murdoch, Western \\ Australia, Australia and 'School of Biological Sciences, University of Plymouth, Drake Circus, Plymouth, UK
}

In plants, pollen- and seed-dispersal distributions are characteristically leptokurtic, with significant consequences for spatial genetic structure and nearest-neighbour mating. However, most studies to date have been on wind- or insectpollinated species. Here, we assigned paternity to quantify effective pollen dispersal over 9 years of mating, contrasted this to seed dispersal and examined their effects on finescale spatial genetic structure, within the bird-pollinated shrub Banksia hookeriana (Proteaceae). We used 163 polymorphic amplified fragment length polymorphism markers to assess genetic structure and pollen dispersal in a spatially discrete population of 112 plants covering 0.56 ha. Spatial autocorrelation analysis detected spatial genetic structure in the smallest distance class of $0-5 \mathrm{~m}$ $(r=0.025)$, with no significant structure beyond $8 \mathrm{~m}$. Experimentally quantified seed-dispersal distances for 337 seedlings showed a leptokurtic distribution around a median of
$5 \mathrm{~m}$, reaching a distance of $36 \mathrm{~m}$. In marked contrast, patterns of pollen dispersal for 274 seeds departed strikingly from typical near-neighbour pollination, with a distribution largely corresponding to the spatial distribution of plants. We found very high multiple paternity, very low correlated paternity and an equal probability of siring for the 50 closest potential mates. Extensive pollen carryover was demonstrated by multiple siring in 83 of 86 (96.5\%) two-seeded fruits. Highly mobile nectar-feeding birds facilitate this promiscuity through observed movements that were effectively random. As the incidence of bird-pollination is markedly greater in the Southwest Australian Floristic Region than elsewhere, our results have broad and novel significance for the evolution and conservation for many species in Gondwanan lineages.

Heredity (2009) 102, 274-285; doi:10.1038/hdy.2008.118; published online 12 November 2008

Keywords: paternity; pollen dispersal; seed dispersal; bird pollination; AFLP; spatial genetic structure

\section{Introduction}

The processes that affect, and are affected by, the spatial arrangement of genetic variation within natural populations, and their consequences for the evolution of biodiversity, are fundamental issues in ecology and evolutionary biology. Spatial genetic structure is determined largely by the interplay between dispersal, selection, genetic drift and the spatial arrangement of individuals (Wright, 1969; Loveless and Hamrick, 1984). In seed plants, the relationship between genetic structure and dispersal is complicated by the possibility of gene movement via both seeds and pollen (Levin and Kerster, 1974). Disentangling the relative contributions of these two agents to total dispersal and to spatial genetic structure

Correspondence: Dr SL Krauss, Botanic Gardens and Parks Authority, Kings Park and Botanic Garden, Fraser Avenue, West Perth, Western Australia 6005, Australia.

E-mail siegy.krauss@bgpa.wa.gov.au

Received 16 May 2008; revised 12 October 2008; accepted 19 October 2008; published online 12 November 2008 remains a major challenge (Fenster, 1991; Ennos, 1994; Ouborg et al., 1999; Fenster et al., 2003; Petit et al., 2005).

According to models of isolation by distance (Wright, 1946; Rousset, 1997), spatially limited dispersal in the absence of selection results in a negative relationship between genetic similarity of individuals and geographic distance (Malecot, 1969; Epperson, 1990, 2007). For plants with typically leptokurtic dispersal (Levin and Kerster, 1974; Loveless and Hamrick, 1984; Vekemans and Hardy, 2004), local genetic structure arises such that populations consist of a continuum of smaller genetic neighbourhoods correlated with the dispersal curve (Wright, 1946; Turner et al., 1982; Crawford, 1984; Epperson, 2007). A convenient and common measure of this spatial genetic structure is Wright's genetic neighbourhood $\left(N_{\mathrm{b}}\right)$. This is defined as the area from which the parents of central individuals may be treated as if drawn at random, and can be determined by the variances of pollen and seed dispersal around a mean of 0 (Wright, 1946; Crawford, 1984).

However, the immobility of plants restricts their mating opportunities severely (Crawley, 1997) and 
random mating is rarely achieved in natural populations. Pollen dispersal is restricted by extrinsic forces such as plant density and pollinator movements, so that most pollen grains are typically deposited on nearest neighbours. Consequently, the probability of siring is generally assumed to decrease rapidly with distance between mates (Levin and Kerster, 1974; Webb, 1998). Pollen dispersal between nearest neighbours that are more related than on average across a population promotes biparental inbreeding, and a reinforcement of local spatial genetic structure and genetic neighbourhoods (Turner et al., 1982). These extrinsic forces may be modified by intrinsic plant reproductive characteristics, such as selfincompatibility, mate choice, or inbreeding depression (Waser, 1993), possibly extending the genetic neighbourhood beyond that determined by pollen dispersal alone. Variability in individual reproductive success will also reduce effective genetic neighbourhood size below census size.

Consequently, the interactions between population genetic structure, seed dispersal, pollen dispersal and their effects on realized mating, genetic variation and the evolution of populations are complex, and an understanding relies mostly on the accuracy of estimates of spatial genetic structure and dispersal (Levin, 1981; Ouborg et al., 1999). Highly polymorphic neutral molecular markers facilitate powerful direct, or 'realtime', approaches for elucidating these interactions. For example, there is now a battery of assignment methods (Jones and Ardren, 2003; Manel et al., 2005) that utilize molecular markers to generate information on realized patterns of pollen dispersal through paternity assignment to individual pollen donors. When the pool of candidate parents becomes large, simple exclusion analysis can become impractical, and categorical allocation methods that use likelihood approaches to select the most likely parent from a pool of non-excluded parents are a solution (Meagher, 1986). For example, Gerber et al. (2000) developed and implemented for dominant markers such as amplified fragment length polymorphism (AFLP) a variation of the original likelihood-based approach for determining parentage.

Remarkably, few studies have assessed pollen dispersal and its consequences on genetic structure for species pollinated by birds. For example, in a major review of studies of ecological determinants of genetic structure in plant populations, only 2 of $163(1.2 \%)$ species considered were bird/bat pollinated (Loveless and Hamrick, 1984). This is largely a consequence of the rarity of nectar-feeding birds in temperate latitudes of the northern hemisphere and temperate rainforests of the world, where wind pollination (anemophily) of trees and insect pollination (entomophily) of shrubs dominates, with pollination by vertebrates (zoophily) being generally uncommon (Ford et al., 1979; Proctor et al., 1996).

The incidence of vertebrate pollination syndromes in Australia, however, is markedly greater than elsewhere, perhaps a result of a large allocation of expendable energy on the profuse production of nectar (Orians and Milewski, 2007). In the highly diverse Southwest Australian Floristic Region (SWAFR), an international biodiversity hotspot (Myers et al., 2000), 15\% of 7380 plant species are considered to be bird and/or mammal pollinated, a striking $40 \%$ of which are threatened endemics (Hopper and Gioia, 2004). In contrast, the other major bird-pollinated regions of South Africa and Central America have only around $4 \%$ of their floras bird pollinated (Bawa, 1990; Orians and Milewski, 2007). Observations of highly mobile behaviour by these Australian birds (Collins and Rebelo, 1987; Ramsey, 1989; McGoldrick and MacNally, 1998), and estimates of components of the mating system for bird-pollinated plants (Sampson, 1998; Coates et al., 2007), suggest potentially novel genetic consequences from wide pollen dispersal and promiscuity in these plants.

Here, our objectives were to examine the relationship between spatial genetic structure, effective seed dispersal, realized patterns of mating and effective pollen dispersal in a spatially discrete population of the Western Australian bird-pollinated shrub Banksia hookeriana Meissner (Proteaceae). We used AFLP markers and multivariate spatial autocorrelation analysis (SAA) to characterize genetic structure, and compared this pattern to direct measurements of effective pollen and seed dispersal. Observations of avian foraging behaviour allowed us to interpret these data with respect to interplant movements by the principal pollen vector. As a result, we generate new insights into the role of dispersal in shaping genetic structure, and to the extrinsic forces influencing effective mating patterns, in a bird-pollinated plant species.

\section{Materials and methods}

\section{Study species}

Banksia hookeriana is a woody, non-sprouting (fire-killed), serotinous (canopy-stored seed) shrub up to $3 \mathrm{~m}$ tall $\times 3 \mathrm{~m}$ wide, that is restricted to the fire-prone northern sandplain scrub-heaths of southwestern Australia, $250-330 \mathrm{~km}$ north of Perth (Miller et al., 2007). As a consequence of the undulating landscape within which it occurs, $B$. hookeriana exists at least in part of its range as discrete populations physically separated by uninhabitable interdunal swales of distances ranging from 0.2 to $>1 \mathrm{~km}$ (He et al., 2004; Krauss et al., 2006). Individuals of $B$. hookeriana commence flowering at 4-5 years of age. Flowers are protandrous and grouped into large creamto orange-coloured inflorescence of about 1000 florets (Lamont et al., 2003), with typically many inflorescences per plant that promote geitonogamy. Flowering is largely synchronous, with all flowering plants within a population even-aged and overlapping to some extent in flowering. Plants are capable of pollination by nectarfeeding birds and mammals and insects, particularly bees. Although seemingly self-compatible (Sedgley et al., 1996), complete outcrossing occurs in at least one population of B. hookeriana (Barrett et al., 2005). Ovaries contain two ovules, of which one but usually two develop into seeds. Viable seeds are held dormant within serotinous woody follicles on large infructescences (cones) in the crown of plants for more than 5 years, and up to 12 years of seed production may be stored in this fashion until fire triggers their release (Enright et al., 1996). Fire intervals in B. hookeriana populations average $\sim 13$ years (Miller et al., 2007), so most seeds are released following fire events. Seeds of $B$. hookeriana are winged and dispersed primarily by wind, with a capacity for long-distance dispersal. Population genetic assignment tests in B. hookeriana have indicated a surprisingly high 
frequency (immigration rates of $7 \%$ ) and distance (up to $2.4 \mathrm{~km}$ ) of long-distance dispersal of seeds within a metapopulation area of $3 \times 2 \mathrm{~km}$ (He et al., 2004). Populations establish in a single cohort following fire and consequently are easily aged either directly by counting stem node scars or with the help of available fire history maps.

\section{Seed dispersal}

Seed dispersal was quantified experimentally in situ using seedling distributions around manipulated source plants. The study site was selected on the basis of an immediate post-burn environment and absence of $B$. hookeriana. The day following the burning of the study site in a wildfire, a total of 11 12-year-old plants from a nearby unburnt population were harvested at their bases and transported to the study site. Individual plants were tied to wooden stakes to mimic their natural habit and were placed $200-300 \mathrm{~m}$ apart along a $2.5 \mathrm{~km}$ transect. Seed-bearing cones were torched with a portable gas burner, triggering release of seeds over the next few days. Plants were inspected for seed release 2 weeks later, by which time $90 \%$ of seeds had been released. Seedling establishment was systematically surveyed 9 months later. The locations of all seedlings, dead or alive, were recorded within a $50 \mathrm{~m}$ radius of the source plant using a compass and measuring tape. The dispersal distance of each seedling was assigned to $5 \mathrm{~m}$ distance classes and averaged over all 11 plants.

\section{Genetics—study population and sampling}

For the characterization of spatial genetic structure and pollen dispersal, we selected a discrete population containing 120, 15-year-old $B$. hookeriana individuals within an area of $0.56 \mathrm{ha}(70 \times 80 \mathrm{~m})$, with density, $d=210$ plants ha ${ }^{-1}$ (Figure 1). Owing to the poor health of eight plants, only 112 could be genotyped. There were three $B$. hookeriana plants $35-45 \mathrm{~m}$ from the edge of the study population, and then no others within $250 \mathrm{~m}$. The location of each $B$. hookeriana individual within the study area was mapped, and the average distance between all pairs of plants was $31.6 \mathrm{~m}$ (s.e. $=0.5$ ), with a range from 0.3 to $128 \mathrm{~m}$. For each plant, leaf material was collected and stored in silica gel until DNA was extracted. The serotinous (canopy stored) seed bank was sampled by selecting five plants that displayed the most complete record of on-plant seed storage from nine successive years of mating. Cones representing each of nine years of seed production were collected for each of the five plants. Seeds were germinated on moistened filter paper at $18{ }^{\circ} \mathrm{C}$ and seedlings planted into pots containing a 5:1 mixture of sand and fine mulch before DNA was extracted from fresh leaves according to He et al. (2004).

AFLP was performed as described by Zawko et al. (2001), except that six AFLP primer pairs were used: M-CAG/E-ACT, M-CAG/E-AGG, M-CAG/E-ACC, $\mathrm{M}-\mathrm{CAG} / \mathrm{E}-\mathrm{AAC}, \mathrm{M}-\mathrm{CAG} / \mathrm{E}-\mathrm{ACA}$ and $\mathrm{M}-\mathrm{CAT} / \mathrm{E}-\mathrm{ACC}$. Electropherograms were scored for presence (1) and absence (0) of fragments between 75 and 500 base pairs, and assembled into a binary data matrix. We utilized only AFLP markers with presence frequencies ranging 0.05-0.95 to minimize the risk of using rare false polymorphisms, with little impact on analysis power.

\section{Spatial genetic structure}

Spatial genetic structure within the study population was assessed by spatial SAA using GenAlEx V6 (Peakall and Smouse, 2006), following the procedures of Smouse and Peakall (1999) that allow the multivariate analysis of individual spatial genetic structure for multilocus data sets. Evenly spaced distance classes of $5 \mathrm{~m}$ were chosen. For all pairs of individuals within a distance class, a correlation coefficient $r$ was calculated using formula 15 in Smouse and Peakall (1999). Upper and lower confidence limits, as generated by 999 random permutations of the data, bound the $95 \%$ confidence interval (CI) about the null hypothesis of no spatial structure. In addition, 95\% CIs about $r$ were estimated by bootstrapping. Although caution is required with the interpretation of patch size from correlograms because it is dependent on the properties of sampling and analysis, a complete sampling of all plants within the population, a large number of polymorphic markers, and a stabilizing profile justified the identification of a critical distance in this study (Krauss and Koch, 2004; Vekemans and Hardy, 2004).

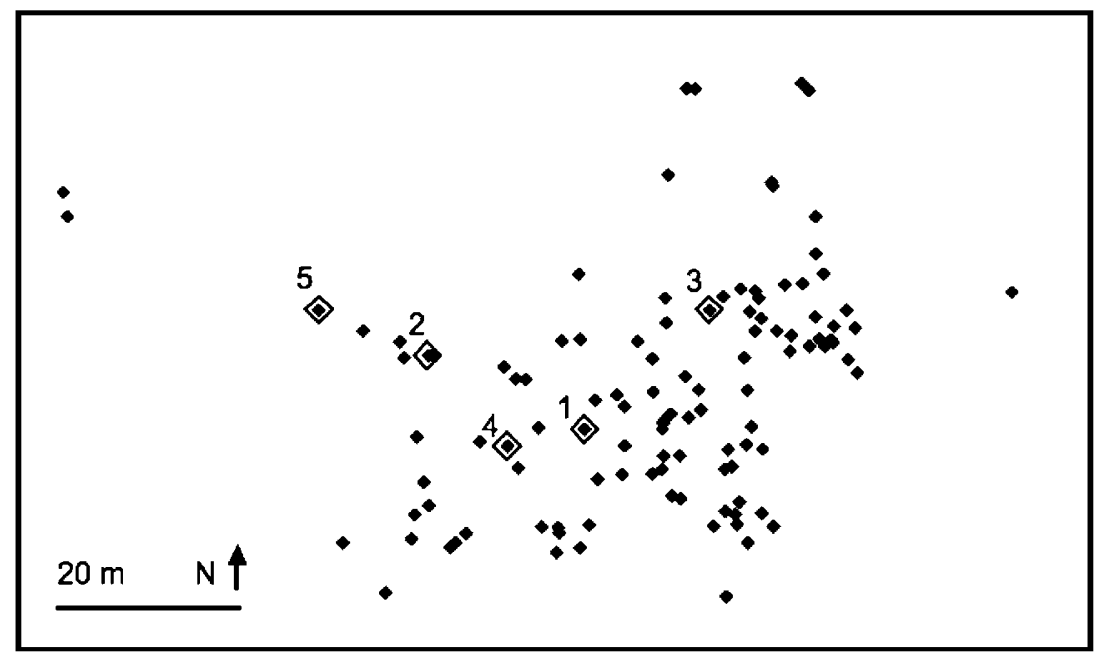

Figure 1 Distribution of 112 Banksia hookeriana plants within the study population at Eneabba, Western Australia. The five plants from which seeds were collected for paternity assignment are indicated. 
We also calculated cumulative estimates of $r$ (along with associated errors about $r$ and the null hypothesis) for increasing distance class sizes using GenAlEx V6 (Peakall and Smouse, 2006). That is, $r$ is calculated for all pairs of individuals in the smallest distance class $(0-5 \mathrm{~m})$, the two smallest distance classes combined $(0-10 \mathrm{~m})$, and so on up to the largest distance class. When significant positive structure is present, the estimated value of $r$ will decrease with increasing size of distance class. The distance class size at which the estimate of $r$ is no longer significant is an estimate of the true extent of detectable positive genetic structure.

In addition, we used SPAGeDi (Hardy and Vekemans, 2002) to characterize spatial genetic structure through their $S_{\mathrm{p}}$ statistic, which is primarily dependent on the rate of decrease of pairwise kinship coefficients between individuals with the logarithm of the distance in two dimensions. Under certain conditions, this statistic estimates the reciprocal of the neighbourhood size (Vekemans and Hardy, 2004). The $S_{\mathrm{p}}$ statistic allows a comparison to other species that is not possible with SAA, and we contrasted our value of $S_{\mathrm{p}}$ to those of 47 other plant species summarized by Vekemans and Hardy (2004).

\section{Paternity analyses}

All paternity analyses were calculated using the software FaMoz (Gerber et al., 2003) according to the categorical allocation likelihood methods described in Gerber et al. (2000). As the maternal plant was known for each offspring, a logarithm of the likelihood ratio (LOD score) was determined as the likelihood of an individual being the sire of a given offspring divided by the likelihood of these two individuals being unrelated. In our calculations, a mistyping error of $3 \%$ was accepted based on our previous results in generating replicate AFLP fingerprints, and reported mistyping rates of AFLP in other studies (Douhovnikoff and Dodd, 2003). We then conducted simulation-based assessments of confidence in paternity assignment by determining an LOD score threshold, as outlined in Gerber et al. (2000, 2003). Therefore, a criterion was determined for deciding whether a given individual would be chosen as the true paternal parent, and the individual with the highest LOD score that was also greater than the threshold was chosen as the true sire for a particular offspring. When all parent-offspring relationships fell below the likelihood threshold, offspring paternity was unassigned.

\section{Pollen dispersal}

The proportion of realized pollen-dispersal distances compared with the proportion of plant pairs was plotted for 5 and $10 \mathrm{~m}$ distance classes for each of the five maternal plants, and for all maternal plants combined. The agreement of the distributions of realized pollen dispersal and plant pair number was assessed by the Kolmogorov-Smirnov two-sample test (Siegel, 1956). For the combined data set (all five maternal plants), we tested whether the mean difference between the fraction of realized pollen-dispersal events and the fraction of plant pairs within each distance class was significantly different from 0 by $t$-test. To standardize for distance, we also plotted siring success as a function of the ranked distance between mates for each maternal plant as well as the combined data set, and assessed the relationship by linear regression analysis.

A two-parameter Weibull function, defined as

$$
f(x)=\frac{c}{b}\left(\frac{x}{b}\right)^{c-1} e^{-(x / b)^{c}}
$$

was used to model the realized dispersal distance distribution for both seed and pollen. The scale parameter, $b$, approximates to the mean dispersal distance, whereas a shape parameter of $c=2$ corresponds to a normal distribution, and $c=1$ to an exponential model. Decreasing $c$ corresponds to fatter-tail functions, and consequently an increasing degree of leptokurtosis. A maximum likelihood method was employed to determine the $c$ and $b$ parameters of the Weibull distribution, using STATISTICA for Windows (Statsoft Inc., 1998).

A measure of the diversity of sires is the correlation of outcrossed paternity $\left(r_{\mathrm{p}}\right)$, or the proportion of pairs of outcrossed progeny that are full sibs, as opposed to halfsibs (Ritland, 1989). This correlation arises from repeated matings to the same near-neighbours, or from the tendency of pollinator pollen loads to be derived from single plants. We used paternity assignments to directly estimate rates of correlated paternity. We used $r_{\mathrm{p}}$ to calculate a paternity pool as $1 / r_{p}$, defined as random mating to an effective pool of neighbours, or the 'effective number of sires' - that is, the number of sires necessary to cause the observed level of correlated mating paternity assuming equal mating chances and independent mating events (Ritland, 1989).

\section{Effective population size}

The relative contributions of seed and pollen dispersal to the genetic neighbourhood $\left(N_{\mathrm{b}}\right)$ inferred by Wright (1946) was estimated by calculating the axial variance $\left(\sigma_{\text {axial }}^{2}\right)$ for each from the sums of dispersal distances $\left(d^{2}\right)$, where $\sigma_{\text {axial }}^{2}=\left(\Sigma d^{2} / n\right) / 2$, and $n$ is the sum of dispersal events measured (Crawford, 1984). The contributions of seed and pollen dispersal to gene dispersal $\left(\sigma_{\mathrm{g}}^{2}\right)$ are additive, and the haploid pollen (p) component halved, so that $\sigma_{\mathrm{g}}^{2}=\left(\sigma_{\mathrm{s}}^{2}\right)+\left(\sigma_{\mathrm{p}}^{2}\right) / 2$ (Vekemans and Hardy, 2004). When dispersal is normally distributed around a mean of 0 , and outcrossing rates are unity, the neighbourhood area can be estimated as $N_{\mathrm{a}}=\pi\left(2 \sigma_{\text {axial (p) }}^{2}\right)+\left(4 \sigma_{\text {axial (s) }}^{2}\right)$ (Crawford, 1984). Estimates of effective neighbourhood size $\left(N_{\mathrm{b}}\right)$ were derived by multiplying $N_{\mathrm{a}}$ by the density of breeding plants $\mathrm{m}^{-2}$.

\section{Bird pollinator movements}

Movements of bird pollinators between $B$. hookeriana plants were examined in an adjoining population of 103 plants within a $35 \times 35 \mathrm{~m}$ area. As this was towards the end of the flowering season, 28 plants were currently flowering (nectar yielding), and only 50 plants had flowered during the current (relatively dry) season. All flowering plants were marked to enable identification, and the number of inflorescences on each plant actively yielding nectar noted. All plants were mapped, and interplant distances calculated. Pollinator movement observations were conducted for a total of $9 \mathrm{~h}$ over 2 days in September 2007, between 0700-1100 and 1500-1800 hours as pollinator activity during the middle of the day was much reduced. Once a bird had begun feeding within the observational area, we noted the number of inflorescences visited on each individual 
plant, the time spent feeding on each inflorescence and whether the bird left the area or moved to another marked plant, in which case the marked plant was noted and observations of inflorescences visited and time spent feeding continued. As the next nearest flowering plant for all individuals was within the observational area, we were thus able to determine whether inter-plant distance (that is, nearest-neighbour proximity) or forage availability (that is, the number of inflorescences available on each flowering plant) influenced the movements of nectar-foraging birds. We observed a total of 74 pollinator visits, all by white-cheeked honeyeaters (Phylidonyris nigra).

\section{Results}

\section{Seed dispersal}

In total, 337 seedlings were located around the 11 parent plants. The seed-dispersal distribution kernel was positively skewed, with mean dispersal distance of $8.12 \mathrm{~m}$ (s.d. $=8.34 \mathrm{~m}$; s.e. $=0.46 \mathrm{~m}$; kurtosis $=1.05$ ), median of $4.9 \mathrm{~m}$ and range from $0.3 \mathrm{~m}$ to a maximum detected seed-dispersal distance of $36 \mathrm{~m}$ (Figure 2). A twoparameter Weibull distribution best fitted the frequency distribution of seed dispersal, with scale parameter $b=10.5$, and shape parameter $c=0.96$. The axial variance of realized seed dispersal $\left(\sigma_{\text {axial (s) }}^{2}\right)$ was $68 \mathrm{~m}$.

\section{Population genetic structure}

Six AFLP primer pairs generated 290 markers from 112 adults and 326 seedlings, of which 163 (56\%) were polymorphic (frequencies between 0.05 and 0.95). Genetic dissimilarity, measured by the number of polymorphic markers between all pairs of adults, varied from 11 to 49 , with a mean of 27. A detailed comparison of genetic diversity between adults and offspring over 9 years of mating is given elsewhere (Barrett et al., 2005).

There was a positive genetic correlation between individuals, when compared with permuted $r$, in the smallest distance class of $5 \mathrm{~m}(P(r<$ permuted $r)=0.01)$ (Table 1). Bootstrap estimates of the $95 \%$ error about

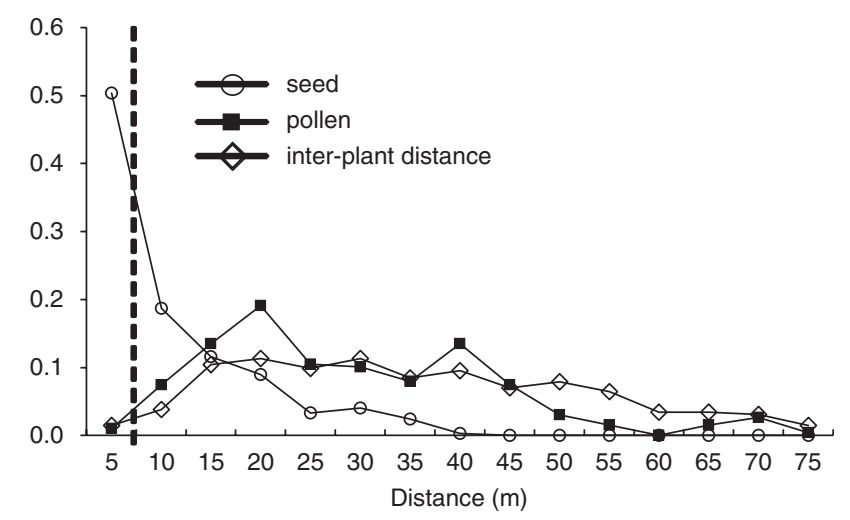

Figure 2 Effective seed- and pollen-dispersal in Banksia hookeriana, showing the proportion of dispersal events for each $5 \mathrm{~m}$ distance class. Vertical dashed line indicates the largest distance at which positive genetic structure was detected by spatial autocorrelation analysis of 163 polymorphic amplified fragment length polymorphism (AFLP) markers in a population of 112 plants of B. hookeriana. Frequency distribution of inter-plant distance within this study population is also shown. $r$ showed that $r$ was greater than $0(P<0.05)$. There was no significant correlation at any other distance class, indicating a stabilizing profile. Genetic patch size, defined as where $r$ first passes from significant to nonsignificant within the correlogram, was $8 \mathrm{~m}$. On average, target plants had five neighbours within this distance, although this ranged from 1 (plant 5) to 10 (plant 3) across the five maternal plants. The graph of $r$ calculated for increasing distance classes confirms weak but positive significant genetic correlation between pairs of individuals at the smallest distance class $(5 \mathrm{~m})$, and no significant genetic correlation (or only weakly so) at larger distances (Figure 3). This result supports the conclusion of patch size between 5 and $10 \mathrm{~m}$. However, in absolute terms, all $r$ values, even that at $5 \mathrm{~m}$, were low, reflecting overall weak genetic structure. This conclusion of weak (but detectable) spatial genetic structure was supported by the estimate of $S_{\mathrm{p}}=0.004 \quad($ s.e. $=0.0012$ ) from SPAGeDi (Hardy and Vekemans, 2002). Neighbourhood size, as the inverse of $S_{\mathrm{p}}$, was 250, greatly extending beyond the limits of the study population.

\section{Pollen dispersal}

The paternity exclusion probability (EP) for 163 polymorphic markers was high $(\mathrm{EP}=0.998)$. Simulation tests using FaMoz gave a threshold likelihood ratio value of 2.5. Using this threshold, maximum likelihood assignment for 326 offspring gave $52(16 \%)$ with no compatible sire among the sampled population, and 274 (84\%) with a most-likely sire within the study population. For these 274 offspring assigned paternity, $114(42 \%)$ had only one potential sire above the threshold. For the remainder, more than one potential sire surpassed the threshold, and we assigned paternity to the most likely sire. For the offspring of these five maternal plants, the percentage of sires within the study population (84\%) equates approximately to the definition of a genetic neighbourhood size as a circle whose radius is equivalent to twice the standard deviation of the gene dispersal distance, or $86.5 \%$ of the parents of an individual at its centre (Wright, 1946; Levin and Kerster, 1974).

Of the 326 seedlings, 178 were from 89 follicles that each contained two seeds. For three of these, both seeds were assigned the same sire, whereas different sires were assigned for each seed in 58 follicles, paternity was assigned for just one seed in 25 of the follicles, and paternity was not assigned for either seed in the remaining three follicles. Consequently, 83 of $86(96.5 \%)$ of two-seeded fruits were shown to be multiply sired. In no case was paternity assigned to the maternal plant (that is, self), indicating complete outcrossing in this population. All seeds had a minimum of 7, and up to 34, non-maternal markers, with a mean of 21 .

Within the two-seeded $B$. hookeriana fruits, correlated paternity $\left(r_{\mathrm{p}}\right)$ could only be either 1 or 0 , but averaged a very low 0.035 across 86 two-seeded fruits: only $3.5 \%$ of two-seeded fruits contained full-sibs. Over the whole plant, correlated paternity $\left(r_{\mathrm{p}}\right)$ varied from 0.018 to 0.059 across five maternal plants, and averaged 0.037 (s.e. $=0.001)$. That is, on average, only $3.7 \%$ of all seed pairs on a $B$. hookeriana plant were full sibs, and this percentage varied little across five maternal plants, despite marked differences in the spatial arrangement of plants around each maternal plant (Figure 1). Our 
Table 1 Spatial autocorrelation analysis results for 163 polymorphic AFLP markers scored for a population of 112 plants of Banksia hookeriana

\begin{tabular}{lcrrrrrrrrrrr}
\hline Distance class & $0-5$ & $5-10$ & $10-15$ & $15-20$ & $20-25$ & $25-30$ & $30-35$ & $35-40$ & $40-45$ & $45-50$ & $50-55$ & $55-60$ \\
\hline$n$ & 204 & \multicolumn{1}{c}{430} & 602 & 670 & \multicolumn{1}{c}{753} & \multicolumn{1}{c}{726} & 598 & \multicolumn{1}{c}{484} & \multicolumn{1}{c}{424} & 345 & 270 \\
$r$ & 0.025 & 0.001 & 0.007 & 0.002 & -0.003 & -0.001 & -0.005 & -0.001 & 0.001 & -0.002 & 0.001 & 0.000 \\
$U$ & 0.013 & 0.010 & 0.008 & 0.009 & 0.007 & 0.009 & 0.007 & 0.010 & 0.011 & 0.010 & 0.013 \\
$L$ & -0.012 & -0.009 & -0.009 & -0.008 & -0.008 & -0.008 & -0.010 & -0.010 & -0.011 & -0.012 & -0.014 & -0.012 \\
$P$ & 0.010 & 0.440 & 0.050 & 0.310 & 0.800 & 0.590 & 0.930 & 0.550 & 0.420 & 0.630 & 0.440 & 0.420 \\
\hline
\end{tabular}

AFLP, amplified fragment length polymorphism. Shown, for each distance class (in metres), are number of pairwise comparisons ( $n$ ), genetic correlation $(r)$, upper $(U)$ and lower $(L)$ bounds for the $95 \%$ confidence interval about the null hypothesis of no spatial structure $(r=0)$, and the probability $(P)$ of a one-tailed test for positive autocorrelation.

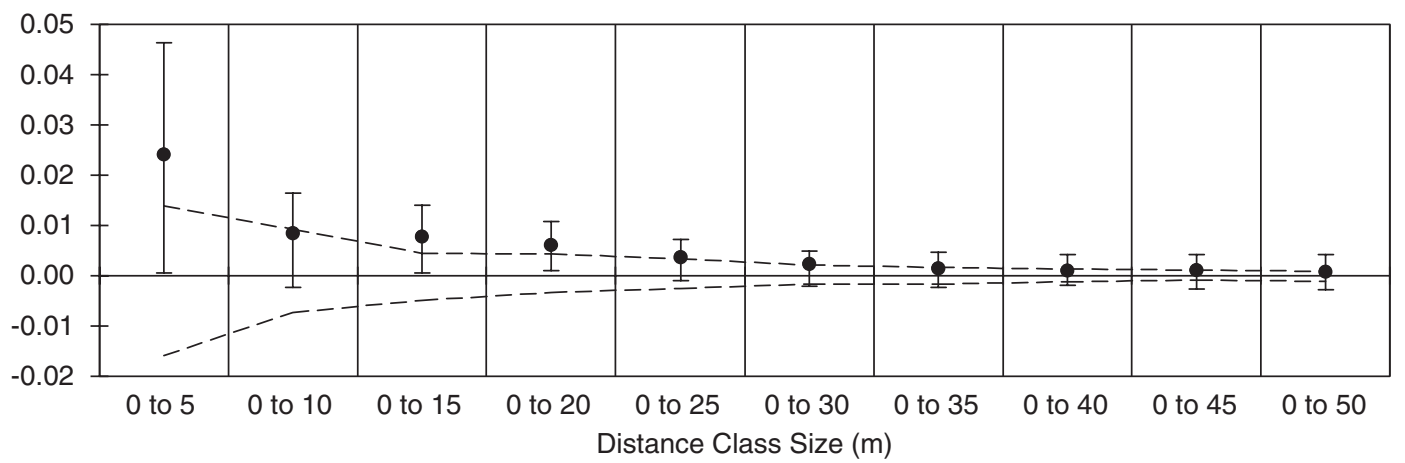

Figure 3 Genetic correlation coefficient $(r)$ for increasing distance class sizes, 95\% CI about the null hypothesis of a random distribution of genotypes, and 95\% confidence error bars about $r$ as determined by bootstrapping (with 999 simulations), for 163 polymorphic amplified fragment length polymorphism (AFLP) markers scored in a population of 112 plants of Banksia hookeriana.

Table 2 Multiple paternity, as determined by maximum likelihood paternity assignment across five families of Banksia hookeriana

\begin{tabular}{lcccc}
\hline $\begin{array}{l}\text { Maternal } \\
\text { plant }\end{array}$ & $\begin{array}{c}\text { No. of offspring assigned } \\
\text { paternity }\end{array}$ & $\begin{array}{c}\text { No. of } \\
\text { sires }\end{array}$ & $\begin{array}{c}\text { Maximum effective pollen grains provided by a single sire (\% of total } \\
\text { offspring) }\end{array}$ & $\begin{array}{c}\text { Mean \# offspring } \\
\text { sired } \pm \text { s.d. }\end{array}$ \\
\hline 1 & 45 & 32 & $4(8.8 \%)$ & $1.4 \pm 0.8$ \\
2 & 48 & 23 & $9(18.8 \%)$ & $2.1 \pm 1.9$ \\
3 & 68 & 28 & $10(14.7 \%)$ & $2.4 \pm 2.3$ \\
4 & 61 & 32 & $9(14.8 \%)$ & $1.9 \pm 1.6$ \\
5 & 52 & 34 & $5(9.6 \%)$ & $1.5 \pm 0.9$ \\
Mean & 55 & 30 & $7(12.7 \%)$ & $1.9 \pm 1.6$ \\
\hline
\end{tabular}

calculation of $r_{\mathrm{p}}=0.037$ equates to an estimate of the effective pool of random mating $\left(1 / r_{\mathrm{p}}\right)$ in $B$. hookeriana of 27 plants.

In total, 75 of $111(67 \%)$ plants sired at least one of the 274 offspring assessed. Multiple paternity within each of the five families was high, with an average of 30 sires for 55 offspring (Table 2). The most successful sire was different across the five families, and ranged from 4 of 45 offspring (8.8\%) to 9 of 48 offspring (18.8\%) (Table 2).

Pollen-dispersal distance was estimated for each offspring as the linear distance between the maternal plant and known sires as determined by paternity assignment, and categorized into $5 \mathrm{~m}$ distance classes (Figure 3). Combining the data for all maternal plants, the distribution of the frequency of mating for each distance class was skewed (skewness coefficient $=0.764 \pm 0.147$ ) with most mating events occurring at an intermediate distance $(15-20 \mathrm{~m})$, rather than in the smallest distance classes (Figure 2). Overall, 10\% of the mating pairs were separated by less than $10 \mathrm{~m}$. The average distance between all pairs of mates was $29.9 \mathrm{~m}$ (average realized pollen- dispersal distance), and the average geographic distance between all pairs of plants was $31.3 \mathrm{~m}$. A twoparameter Weibull distribution function best fitted the frequency distribution of realized pollen dispersal, with scale parameter $(b)$ of 29.5 (equivalent to the average pollen-dispersal distance), and shape parameter (c) of 1.9. The axial variance of realized pollen dispersal $\left(\sigma_{\text {axial }(p)}^{2}\right)$ was $493 \mathrm{~m}$. Combined with the axial variance for seed dispersal, and an assumption that dispersal is normally distributed around a mean of 0 , the estimate of effective neighbourhood size $\left(N_{\mathrm{b}}\right)$ was 83 plants.

Realized pollen-dispersal distributions varied among maternal plants, and appear strongly influenced by the position of the maternal plant within the population (Figure 4). However, in only one maternal plant (two) was the pollen-dispersal distribution significantly different from the physical distribution of plant pairs (Kolmogorov-Smirnov two-sample test, $P<0.001$; Figure 4), indicating no detectable departure from random mating for the offspring from four of five families. Combining all maternal plants, there was a significant departure from random mating (Kolmogorov-Smirnov two-sample test, $P<0.001$ ), with a higher than expected 

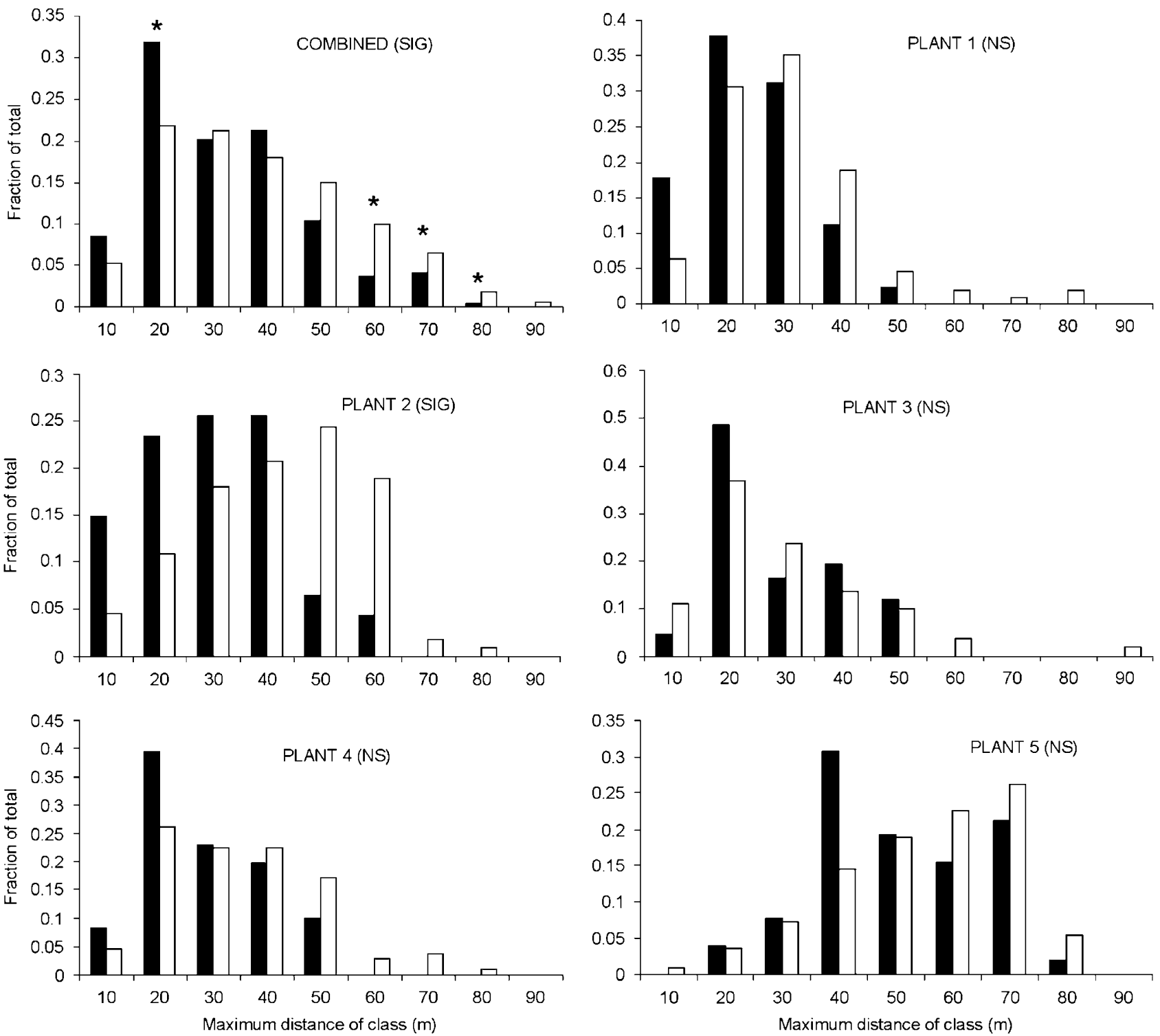

Figure 4 Frequency distribution showing the fraction of 274 effective pollen dispersal events (solid bars) and plant pairs (unfilled bars) for each distance class (upper boundary given) for the combined data set of five maternal plants combined and separate (1-5) in a population of 112 plants of Banksia hookeriana. 'SIG' indicates a significant departure $(P<0.001)$ between the two distributions, 'NS' indicates no significant departure $(P>0.05)$ between the two distributions, as determined by Kolmogorov-Smirnov two-sample tests. Asterisk indicates significant difference $(t$-test, $P<0.05)$ between fraction of effective pollen dispersal and plant pairs within a distance class for the combined data set.

number, under random mating, of mates in the $10-20 \mathrm{~m}$ distance class, and fewer than expected under random mating between 50 and $80 \mathrm{~m}$ (Figure 4). These departures may reflect non-random pollinator movements at these distances. Overall though, the probability of mating is only weakly associated with distance between mates, at least up to an average inter-mate distance of $50 \mathrm{~m}$. Within this study population, that equates to an average for a maternal plant of 50 potential mates of equal age with more or less equal probability of paternity over the 9 years of mating measured.

Mating success as a function of the ranked distance between mates showed a weak but significant negative linear relationship ( $r=0.328 ; P=0.0004)$ (Figure 5). However, this negative relationship is largely realized only beyond the 50th mate pair, as there was no significant relationship for ranked distance and mating success between the first and 50th mate pairs $(r=-0.035$; $P=0.907)$. Up to the 50th mate pair ranked according to distance, the probability of mating for each pair averaged 0.014 . For the 51st-111th mate pair, no relationship was seen between ranked distance and siring success, although the probability of mating for each pair averaged only 0.006. A weak, but significant, negative relationship between mating success and ranked distance between mates was found for maternal plants 1, 2 and 4 (Figure 5). However, there was no such relationship for maternal plants 3 and 5 (Figure 5).

\section{Bird pollinator movements}

Of 74 individual bird visits observed, 50 (68\%) left the population after visiting only a single plant, whereas 24 $(32 \%)$ moved to another plant within the population. The 

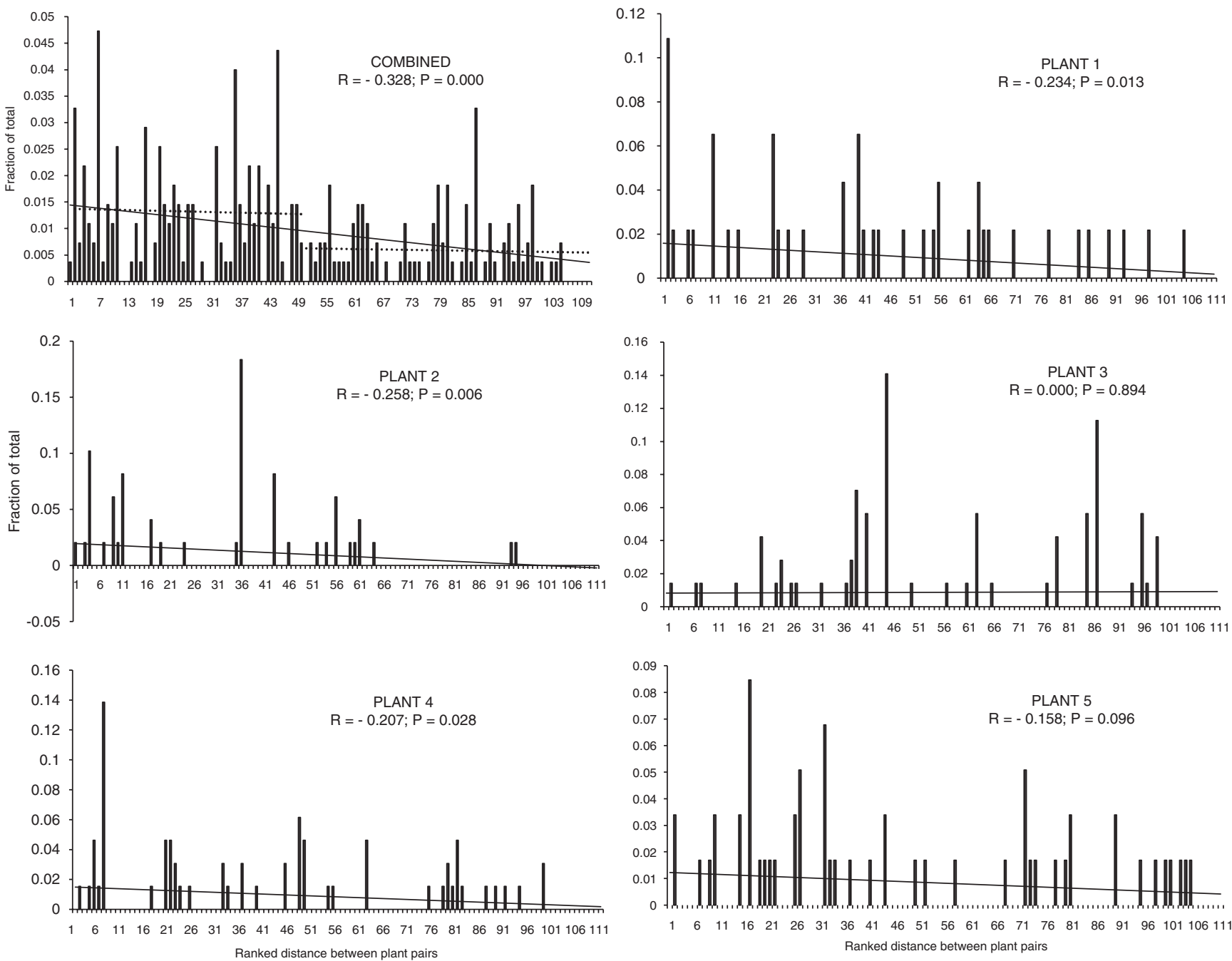

Figure 5 Frequency distribution showing the fraction of 274 effective pollen dispersal events against ranked distance between all plant pairs, for the combined data set of five maternal plants combined and separate (plants 1-5) in a population of 112 plants of Banksia hookeriana. Regression coefficient $(r)$ is shown, and when $P<0.05, r$ is significantly different from 0 . For the combined data set, dotted regression lines indicate no relationship between ranked distance and siring success within ranked distance 1-50, and within ranked distance 51-112.

total number of movements observed within the population was 35 . Of these, significantly fewer $\left(\chi^{2}=10.83\right.$; $P<0.001)$ were to the nearest flowering neighbour $(8,23 \%)$, whereas $27(77 \%)$ were to a non-nearest neighbour. The average distance between all pairs of flowering plants, between nearest flowering neighbours, and of pollinator movements within the population were 16.6 ( \pm 8.0 s.d.), 3.3 ( \pm 1.4 s.d.) and 7.4 ( \pm 3.6 s.d.) $\mathrm{m}$, respectively. There was a significant correlation $(r=0.439 ; P<0.05)$ between the number of open inflorescences on a plant and the number of bird visits to a plant. No relationship was found between movement and direction. Taken together, these observations suggest that bird movements within this population were influenced more by flowering intensity than plant proximity.

\section{Discussion}

Effective pollen dispersal in B. hookeriana showed a striking departure from the predominantly nearestneighbour mating that is typical of plants pollinated by wind and insect vectors. Furthermore, we found exceptionally high multiplicity of paternity, very low correlated paternity, and a probability of mating locally that showed a weak linear, rather than leptokurtic, relationship with ranked distance between mates detected across the entire population of 112 plants. An average probability of siring was found to be equivalent for the 50 most proximate potential sires around a maternal plant, and is to our knowledge an observation of random mating unmatched in the pollen-dispersal literature.

\section{Genetic neighbourhood}

Consistent with this panmixis, the contribution of pollen dispersal to the estimate of Wright's neighbourhood size $\left(N_{\mathrm{b}(\mathrm{p})}=4 \pi\left(\sigma_{\mathrm{p}}^{2} / 2\right)\right)$ was 65 plants. As a consequence of this panmixis, and despite highly restricted and typically leptokurtic primary seed dispersal, the ratio of effective to census population size $\left(N_{\mathrm{b}} / N=83 / 112=0.74\right)$ was strikingly greater than the average $\left(N_{\mathrm{e}} / N=0.1\right)$ for more than 100 species of animals and plants reported by 
Frankham (1995). However, comparison with the indirect estimate of neighbourhood size (inverse of $S_{\mathrm{p}}$ ) suggests that the direct estimate, $N_{\mathrm{b}}$, may significantly underestimate effective population size, in contrast to studies on other species that have found equivalent direct and indirect estimates (Fenster, 1991; Fenster et al., 2003). A marked departure from the assumption of normally distributed dispersal in the calculation of $N_{\mathrm{b}}$, as well as a population that is not in drift migration equilibrium, may largely explain the discrepancy between these direct and indirect estimates. In addition, these direct and indirect estimates are 'real-time' and historical measures respectively, and accumulated dispersal over many generations is apparently even greater than that observed directly. Therefore, the indirect estimate accounts for all possible causes of variation in effective and census population size, whereas the direct estimate is restricted to the spatial limitation of local seed and pollen dispersal with distance (Vekemans and Hardy, 2004).

Neighbourhood size, estimated indirectly as $1 / S_{p}=250$, greatly exceeded the limits of the study population, and highlights the importance of metapopulation dynamics in this species. This is strongly supported by our observations of high between population pollinator movement rates, high levels of interpopulation pollen dispersal (16\% of offspring with no compatible sire from the sampled population) and surprisingly high inter-population seed-dispersal rates, where $7 \%$ of individuals were inferred to be seed immigrants (He et al., 2004). The direct estimate of neighbourhood size does not incorporate this gene flow, whereas the indirect estimate does.

\section{Spatial genetic structure}

Spatial genetic structure in this population of $B$. hookeriana, as measured by the $S_{\mathrm{p}}$ statistic, was among the weakest yet recorded (Vekemans and Hardy, 2004). For 47 plant species reviewed by Vekemans and Hardy (2004), $S_{\mathrm{p}}$ ranged from 0.0003 to 0.263 , with an average $(0.030 \pm 0.049$ (s.d.)) an order of magnitude greater than that detected for B. hookeriana here $\left(S_{p}=0.004\right)$. Again, this result is striking given the restricted primary seed dispersal and considering the average $S_{\mathrm{p}}$ for six gravitydispersed seed species of 0.028 (Vekemans and Hardy, 2004). Although $S_{\mathrm{p}}$ indicated overall weak genetic structure in our $B$. hookeriana population, the impact of narrow seed dispersal was apparent in the SAA, which resolved spatial genetic structure to a distance of $8 \mathrm{~m}$ (an average patch size of five plants), and a stabilizing profile with no structure beyond. An explanation for this spatial genetic structure therefore lies in the contrasting impacts of pollen and seed dispersal, where $\sigma_{\mathrm{p}}^{2} / \sigma_{\mathrm{s}}^{2}=7.25$, and the random mating that is facilitated primarily by the behaviour of highly mobile nectar-feeding birds as pollinators.

\section{Pollen dispersal}

The pattern of pollen dispersal we detected in $B$. hookeriana departs from theoretical models of pollen dispersal, as well as from empirically determined pollendispersal distributions estimated for insect- and windpollinated species (Levin and Kerster, 1974; Levin, 1981; Proctor et al., 1996; Smouse et al., 1999; Sork et al., 2002; Austerlitz et al., 2004; Smouse and Sork, 2004; Vekemans and Hardy, 2004). The shrub Persoonia mollis (Proteaceae), for example, is pollinated by a suite of bees such as Leioproctus spp., and paternity analysis has identified the typically leptokurtic pollen-dispersal curve in this species, where first-order nearest neighbours, and firstto third-order nearest neighbours, sired 50 and $70 \%$, respectively, of all seeds (Krauss, 2000). Similarly, in the wind-pollinated Pinus sylvestris, first-order nearest neighbours, and first- to third-order nearest neighbours, sired 25 and $42 \%$ of all seeds, respectively (RobledoArnuncio and Gil, 2005). In contrast, first-order nearest neighbours in $B$. hookeriana sired on average two orders of magnitude fewer $(0.5 \%)$ of the total seeds assessed, whereas first- to third-order nearest neighbours sired only $4.4 \%$ of all seeds. Whereas pollen-dispersal distances can be very high for widely dispersed plants (for example, $23 \mathrm{~km}$ for species pollinated by euglossine bees in tropical rainforests; Janzen, 1971), the dispersal kernel remains typically leptokurtic (Janzen, 1971; Bawa, 1990; Proctor et al., 1996). Although some recent paternity studies have shown surprisingly long pollen-dispersal distances (Kramer et al., 2008), nearest-neighbour pollination, whereas not universal (Broyles and Wyatt, 1991; Dick et al., 2003), is clearly a generally observed phenomenon in pollination biology (Webb, 1998), from which $B$. hookeriana is a notable exception.

A genetic consequence of nearest-neighbour pollination is higher correlated paternity, where full-sib pairs are usually sired by nearest neighbours. This relationship serves to amplify the genetic structuring effects of nearest-neighbour pollination. In contrast, near random mating in $B$. hookeriana resulted in very low correlated paternity $\left(r_{\mathrm{p}}=0.037\right)$, that to our knowledge is the lowest recorded, and a value that is an order of magnitude less than typical measures (Sampson, 1998). A departure from nearest-neighbour pollination has been previously observed (Broyles and Wyatt, 1991) when pollen has been packaged into discrete bundles (pollinia). In this case, however, multiple paternity within fruits is almost non-existent, and correlated paternity is near to or equal to unity (that is, all seeds within a fruit are full sibs), with significant consequences for spatial genetic structure.

\section{Pollen vectors}

The panmixis we detected requires extensive pollen carryover and/or near random pollinator foraging behaviour, in terms of both distance and direction. Such features are generally considered unlikely in zoophilous plant species (Levin and Kerster, 1974). Our observation that $96 \%$ of two-seeded fruits were multiply sired indicates extensive pollen carryover in this population. In B. hookeriana, pollination is achieved primarily through nectar-feeding birds in the family Meliphagidae. These include the White-Cheeked Honeyeater ( $P$. nigra), Tawny-crowned Honeyeater ( $P$. melanops), Red Wattlebird (Anthochaera carunculata) and the Brown Honeyeater (Lichmera indistincta) (Brown et al., 1997). Indeed, nectarfeeding birds routinely pollinate many Banksia species (Ford et al., 1979; Hopper, 1980; Collins and Rebelo, 1987; Taylor and Hopper, 1988; Ramsey, 1989; Day et al., 1997; Wooller and Wooller, 2004). Although the honey possum, Tarsipes rostratus is also an important pollinator for many southwestern Australian banksias (Wiens et al., 1979; Bradshaw and Bradshaw, 2002), studies of foraging 
movements of $T$. rostratus suggest that it does not generally achieve the long-realized pollen-dispersal distances inferred here (Bradshaw and Bradshaw, 2002). Insects (predominantly native bees such as the banksia bee Hylaeus alcyoneus (Houston, 2000) and the introduced honeybee Apis mellifera) visit flowers, but winter flowering of $B$. hookeriana restricts the abundance of insects as potential pollinators.

\section{Consequences of pollination by nectar-feeding honeyeaters}

A major feature of bird-pollinated plants in temperate southern Australia is a patchy, asynchronous flowering of different species, which is a principal driver of mass nomadism of nectarivorous birds among regions and habitats (McGoldrick and MacNally, 1998). Thus, most honeyeaters are highly mobile generalist foragers well adapted to the heterogeneous flowering landscape over which nectar is produced (Ford et al., 1979; McGoldrick and MacNally, 1998). In our study, this was demonstrated by $77 \%$ of all within-population bird movements being beyond nearest neighbours, and $68 \%$ of observed movements leaving the local population. Energy requirements for individual nectar-feeding birds demonstrate a need for movement between a large number of plants, and often species (Collins and Rebelo, 1987). High mobility and aggressive spatial displacement behaviour of honeyeaters competing for the same resource largely explains the patterns of pollen dispersal and pollen carryover we detected. In contrast, most (but not all) hummingbirds display conspicuous aggressive behaviour in the defence of small-feeding territories, and coupled with nearest-neighbour optimal foraging, this restricts the dispersal of pollen for plants pollinated by these birds (Pyke, 1980; Proctor et al., 1996).

Part of the pattern of pollen dispersal can also be attributed to limited co-flowering within the population, obliging birds to move beyond the next plant on those grounds alone. Our observation of 27\% co-flowering in this study can be compared with 32, 61 and $69 \%$ co-flowering plants in other studied populations of B. hookeriana at the peak of flowering (with $98 \%$ flowering over the entire season; Lamont et al., 2003). Aggregation of flowers into a few dense inflorescences is typical of many bird-pollinated species, decreasing the chances of co-flowering and increasing the distance between potential mates. Birds often flew over flowering plants in search of those with greater nectar rewards. However, we have also demonstrated that the accumulation of 9 years of mating smoothes out the year-to-year pollen pool variation that may result from sporadic flowering (this study; Barrett et al., 2005). Indeed, in B. hookeriana, genetic variation in the aerial seed bank approached a maximum after only a few years of mating, suggesting that random mating is achieved quickly (Barrett et al., 2005).

In Australia, nectarivores are a conspicuous component of avian communities as a result of the profuse production of nectar and relatively few fleshy-fruited plants (Orians and Milewski, 2007). Consequently, bird pollination is a prominent feature of the flora of temperate Australia, especially in the ancient Gondwanan families Proteaceae and Myrtaceae (Ford et al., 1979; Keighery, 1980). Over 110 species of birds have been recorded visiting the flowers of 1000 species of plants in more than 64 genera and 16 families (Ford et al., 1979; Keighery, 1980; Brown et al., 1997). Many of these genera (for example, Banksia, Grevillea, Melaleuca, Eucalyptus) are highly diverse and abundant. Significantly, the large number of species pollinated by nectarivores suggests that the wide pollen-dispersal patterns we have detected, and its consequences for mating, genetic variation and genetic structure, may be a common feature of pollination for many plant species in temperate Australia. We suggest, then, that nectar-feeding bird pollination in southern temperate zones is a significant pollination syndrome with poorly understood, yet potentially novel, genetic consequences. These included wide outcrossing, multiplicity of paternity, low correlated paternity, weak genetic structure and the maintenance of genetic variation that may not be accurately predicted if applying generally accepted models of pollen dispersal based largely on wind and insect pollination.

Our observations raise intriguing suggestions that the honeyeater pollination syndrome can be characterized by ecological attributes that distinguish it from other pollination syndromes in promoting wide outcrossing. These include flowers typically in dense inflorescences, plants in a population tending not to all co-flower, highly mobile pollinators displaying movements beyond nearest plant neighbours, pollinators carrying high pollen loads from multiple plant visits and aggressive spatial displacement among birds promoting highly dynamic activity. Our direct observations of the majority of all bird movements to beyond the study population suggests that long-distance pollen flow among populations may also be a characteristic feature of this syndrome. In support, our genetic data showed that $52(16 \%)$ offspring did not have a compatible sire within the known pollen pool, and Byrne et al. (2007) found an average of $33 \%$ of seedlings sired by pollen sources outside of the study population, at distances of up to $5 \mathrm{~km}$, in the Western Australian bird-pollinated shrub Calothamnus quadrifidus. In addition, our study population was relatively small (He et al., 2004), and wide outcrossing and multiplicity of paternity is likely to be even more pronounced in typically larger populations.

\section{Conservation implications}

An immediate challenge of some urgency is to understand how human-induced alterations to the natural distribution and abundance of plant species and their bird pollinators affect dispersal and plant-pollinator interactions (Saunders and Ingram, 1995; Kearns et al., 1998; Paton, 2000). Recent genetic studies on other birdpollinated plants in the SWAFR have demonstrated an impact on the mating system, with increased selfing and increased correlated paternity associated with reduced population size following habitat fragmentation (Coates et al., 2007). Introduced, non-native pollinators such as European honeybees (A. mellifera), and increased competition for declining vertebrate pollinators, strongest in biodiversity hotspots (Vamosi et al., 2006), affect pollen limitation and seed set in many species with already low conversions of flowers to fruits (Ayre and Whelan, 1989; England et al., 2001), increasing extinction risk. Our results highlight the additional conservation genetic concerns from bird-pollinator disruption that may result 
in a significant increase in near-neighbour pollen dispersal, correlated paternity and inbreeding through bi-parental mating. In these widely outcrossing species, genetic load is high, and inbreeding depression strong (Heliyanto et al., 2006). These potentially detrimental genetic impacts will be of greatest concern in species characterized by promiscuity, likely to be a feature of the highly diverse bird-pollinated flora of the SWAFR.

\section{Acknowledgements}

This research was supported by Australian Research Council grants DP0211759 and DP0556767, and a Royal Society (London) grant to MEH. We thank Steve Hopper, Don Bradshaw, Ryan Phillips and two anonymous referees for helpful comments on the paper, Peter Mioduszewski for assistance in the glasshouse, Robyn Taylor, Madeleine Parent, Wesley Lamont, Guiseppe Messina, and Alan and Lorraine Tinker, for technical, field and logistic assistance, and the Western Australian Department of Environment and Conservation for permission to work in reserves under its management.

\section{References}

Austerlitz F, Dick CW, Dutech CF, Klein EK, Oddou-Muratorio $\mathrm{S}$, Smouse PE et al. (2004). Using genetic markers to estimate the pollen dispersal curve. Mol Ecol 13: 937-954.

Ayre DJ, Whelan RJ (1989). Factors controlling fruit set in hermaphroditic plants: studies with the Australian Proteaceae. Trends Ecol Evol 4: 267-272.

Barrett LG, He TH, Lamont BB, Krauss SL (2005). Temporal patterns of genetic variation across a 9-year-old aerial seed bank of the shrub Banksia hookeriana (Proteaceae). Mol Ecol 14: 4169-4179.

Bawa KS (1990). Plant-pollinator interactions in tropical rainforests. Ann Rev Ecol Syst 21: 399-422.

Bradshaw SD, Bradshaw FJ (2002). Short-term movements and habitat use of the marsupial honey possum (Tarsipes rostratus). J Zool Lond 258: 343-348.

Brown EM, Burbidge AH, Dell J, Edinger D, Hopper SD, Wills RT (1997). Pollination in Western Australia: A Database of Animals Visiting Flowers. WA Naturalists' Club: Perth.

Broyles SB, Wyatt R (1991). Effective pollen dispersal in a natural population of Asclepias exaltata: the influence of pollinator behaviour, genetic similarity, and mating successs. Am Nat 138: 1239-1249.

Byrne M, Elliot CP, Yates CJ, Coates DJ (2007). Extensive pollen dispersal in a bird-pollinated shrub, Calothamnus quadrifidus, in a fragmented landscape. Mol Ecol 16: 1303-1314.

Coates DJ, Sampson JF, Yates CJ (2007). Plant mating systems and assessing population persistence in fragmented landscapes. Aust J Bot 55: 239-249.

Collins BG, Rebelo T (1987). Pollination biology of the Proteaceae in Australia and southern Africa. Aust J Ecol 12: 387-421.

Crawford TJ (1984). The estimation of neighbourhood parameters for plant populations. Heredity 53: 273-283.

Crawley MJ (1997). Sex. In: Crawley MJ (ed). Plant Ecology, 2nd edn. Blackwell Scientific: Oxford. pp 156-213.

Day DA, Collins BG, Rees RG (1997). Reproductive biology of the rare and endangered Banksia brownii Baxter ex R. Br. (Proteaceae). Aust J Ecol 22: 307-315.

Dick CW, Etchelecu G, Austerlitz F (2003). Pollen dispersal of tropical trees (Dinizia excelsa: Fabaceae) by native insects and African honeybees in pristine and fragmented Amazonian rainforest. Mol Ecol 12: 753-764.

Douhovnikoff V, Dodd RS (2003). Intra-clonal variation and a similarity threshold for identification of clones: application to
Salix exigua using AFLP molecular markers. Theor Appl Genet 106: 1307-1315.

England PR, Beynon F, Ayre DJ, Whelan RJ (2001). A molecular genetic assessment of mating-system variation in a naturally bird-pollinated shrub: contributions from birds and introduced honeybees. Conserv Biol 15: 1645-1655.

Ennos RA (1994). Estimating the relative rates of pollen and seed migration among plant populations. Heredity 72: 250-259.

Enright NJ, Lamont BB, Marsula M (1996). Canopy seed bank dynamics and optimum fire regime for the highly serotinous shrub, Banksia hookeriana. J Ecol 84: 9-17.

Epperson BK (1990). Spatial patterns of genetic variation within plant populations. In: Brown AHD, Clegg MT, Kahler AL, Weir BS (eds). Plant Population Genetics, Breeding and Genetic Resources. Sinauer: Sunderland, MA. pp 229-253.

Epperson BK (2007). Plant dispersal, neighbourhood size and isolation by distance. Mol Ecol 16: 3854-3865.

Fenster CB (1991). Gene flow in Chamaecrista fasciculata (Leguminosae) I. Gene dispersal. Evolution 45: 398-409.

Fenster CB, Vekemans X, Hardy OJ (2003). Quantifying gene flow from spatial genetic structure data in a metapopulation of Chamaecrista fasciculata (Leguminosae). Evolution 57: 995-1007.

Ford HA, Paton DC, Forde N (1979). Birds as pollinators of Australian plants. New Zealand J Bot 17: 509-519.

Frankham R (1995). Effective population size/adult size ratios in wildlife: a review. Genet Res 66: 95-107.

Gerber S, Chabrier P, Kremer A (2003). FAMOZ: a software for parentage analysis using dominant, codominant and uniparentally inherited markers. Mol Ecol Notes 3: 479-481.

Gerber S, Mariette S, Strieff R, Bodénès C, Kremer A (2000). Comparison of microsatellites and amplified fragment length polymorphism markers for parentage analysis. Mol Ecol 9: 1037-1048.

Hardy OJ, Vekemans X (2002). SPAGeDi: a versatile computer program to analyse spatial genetic structure at the individual or population levels. Mol Ecol Notes 2: 618.

He T, Krauss SL, Lamont BB, Miller BP, Enright NJ (2004). Long distance seed dispersal in a metapopulation of Banksia hookeriana inferred from a population allocation analysis of AFLP data. Mol Ecol 13: 1099-1109.

Heliyanto B, Krauss SL, Lambers H, Cawthray GR, Veneklaas EJ (2006). Increased ecological amplitude through heterosis following wide outcrossing in Banksia ilicifolia (Proteaceae). J Evol Biol 19: 1327-1338.

Hopper SD (1980). Bird and mammal pollen vectors in Banksia communities at Cheyne Beach, Western Australia. Aust J Bot 28: 61-75.

Hopper SD, Gioia P (2004). The southwest Australian floristic region: evolution and conservation of a global hot spot of biodiversity. Ann Rev Ecol Evol Syst 35: 623-650.

Houston TF (2000). Native Bees on Wildflowers in Western Australia. The Western Australian Insect Society Inc.: Perth, Western Australia.

Janzen DH (1971). Euglossine bees as long-distance pollinators of tropical plants. Science 171: 203-205.

Jones AG, Ardren WR (2003). Methods of parentage analysis in natural populations. Mol Ecol 12: 2511-2523.

Kearns CA, Inouye DW, Waser NM (1998). Endangered mutualisms: the conservation of plant-pollinator interactions. Ann Rev Ecol Syst 29: 83-112.

Keighery GJ (1980). Bird pollination in South Western Australia: a checklist. Plant Syst Evol 135: 171-176.

Kramer AT, Ison JL, Ashley MV, Howe HF (2008). The paradox of forest fragmentation genetics. Conserv Biol 22: 878-885.

Krauss SL (2000). Patterns of mating in Persoonia mollis (Proteaceae) revealed by an analysis of paternity using AFLP: implications for conservation. Aust J Bot 48: 349-356.

Krauss SL, He TH, Lamont BB, Miller BP, Enright NJ (2006). Late Quaternary climate change and spatial genetic structure in the shrub Banksia hookeriana. Mol Ecol 15: 1125-1138. 
Krauss SL, Koch JM (2004). Rapid genetic delineation of provenance for plant community restoration. J Appl Ecol 41: 1162-1173.

Lamont BB, He TH, Enright NJ, Krauss SL, Miller BP (2003). Anthropogenic disturbance promotes hybridization between Banksia species by altering their biology. J Evol Biol 16: 551-557.

Levin DA (1981). Dispersal versus gene flow in plants. Ann Missouri Botanic Gardens 68: 233-253.

Levin DA, Kerster HW (1974). Gene flow in seed plants. Evol Biol 7: 139-220.

Loveless MD, Hamrick JL (1984). Ecological determinants of genetic structure in plant populations. Ann Rev Ecol Syst 15: 65-95.

Malecot G (1969). The Mathematics of Heredity. W.H. Freeman: San Francisco.

Manel S, Gaggiotti OE, Waples RS (2005). Assignment methods: matching biological questions with appropriate techniques. Trends Ecol Evol 20: 136-142.

McGoldrick JM, MacNally R (1998). Impact of flowering on bird community dynamics in some central Victorian eucalypt forests. Ecol Res 13: 125-139.

Meagher TR (1986). Analysis of paternity within a natural population of Chamaelirium luteum. I. Identification of mostlikely male parents. Am Nat 128: 199-215.

Miller BP, Enright NJ, Lamont BB (2007). Record error and range contraction, real and imagined, in the restricted shrub Banksia hookeriana in south-western Australia. Divers Distrib 13: 406-417.

Myers N, Mittermeier RA, Mittermeier CG, da Fonseca GAB, Kent J (2000). Biodiversity hotspots for conservation priorities. Nature 403: 803-808.

Orians GH, Milewski AV (2007). Ecology of Australia: the effects of nutrient-poor soils and intense fires. Biol Rev 82: 393-423.

Ouborg HJ, Piquot Y, van Groenendael JM (1999). Population genetics, molecular markers and the study of dispersal in plants. J Ecol 87: 551-568.

Paton DC (2000). Disruption of bird-plant pollination systems in southern Australia. Conserv Biol 14: 1232-1234.

Peakall R, Smouse PE (2006). GenAlEx 6: genetic analysis in excel. Population genetic software for teaching and research. Mol Ecol Notes 6: 288-295.

Petit RJ, Duminil J, Fineschi S, Hampe A, Salvini D, Vendramin GG (2005). Comparative organization of chloroplast, mitochondrial and nuclear diversity in plant populations. Mol Ecol 14: 689-701.

Proctor M, Yeo P, Lack A (1996). The Natural History of Pollination. Timber Press: Portland, OR.

Pyke GH (1980). The foraging behaviour of Australian honeyeaters: a review and some comparisons with hummingbirds. Aust J Ecol 5: 343-369.

Ramsey MW (1989). The seasonal abundance and foraging behaviour of honeyeaters and their potential role in the pollination of Banksia menziesii. Aust J Ecol 14: 33-40.

Ritland K (1989). Correlated matings in the partial selfer, Mimulus guttatus. Evolution 43: 848-859.

Robledo-Arnuncio JJ, Gil L (2005). Patterns of pollen dispersal in a small population of Pinus sylvestris L. revealed by totalexclusion paternity analysis. Heredity 94: 13-22.

Rousset F (1997). Genetic differentiation and estimation of gene flow from F-statistics under isolation by distance. Genetics 145: $1219-1228$
Sampson J (1998). Multiple paternity in Eucalyptus rameliana (Myrtaceae). Heredity 81: 349-355.

Saunders DA, Ingram JA (1995). Birds of Southwestern Australia. An Atlas of Changes in the Distribution and Abundance of the Wheatbelt Avifauna. Surrey Beatty and Sons: Chipping Norton, NSW.

Sedgley M, Wirthensohn MG, Delaporte K (1996). Interspecific hybridization between Banksia hookeriana Meissn. and Banksia prionotes Lindl. (Proteaceae). Int J Plant Sci 157: 755-762.

Siegel S (1956). Nonparametric Statistics for the Behavioral Sciences. McGraw-Hill Book Company Inc.: New York.

Smouse PE, Meagher TR, Kobak CJ (1999). Parentage analysis of male reproductive contributions in Chamaelirium luteum (L.) Gray (Liliaceae): why do some males have disproportionate reproductive contributions? J Evol Biol 12: 1069-1077.

Smouse PE, Peakall R (1999). Spatial autocorrelation analysis of individual multiallele and multilocus genetic structure. Heredity 82: 561-573.

Smouse PE, Sork VL (2004). Measuring pollen flow in forest trees: an exposition of alternative approaches. Forest Ecol Manag 197: 21-38.

Sork VL, Davis FW, Smouse PW, Apsit VJ, Dyer RJ, Fernadez-M JF et al. (2002). Pollen movement in declining populations of California Valley oak, Quercus lobata: where have all the fathers gone? Mol Ecol 11: 1657-1668.

StatSoft Inc (1998). STATISTICA for Windows (Volume II) Graphics. Tulsa, OK, USA. www.statsoft.com.

Taylor A, Hopper SD (1988). The Banksia Atlas. Australian Flora and Fauna Series 8. Australian Government Printing Service: Canberra.

Turner ME, Claiborne J, Anderson WW (1982). Homozygosity and patch structure in plant population as a result of nearest-neighbour pollination. Proc Natl Acad Sci USA 79: 203-207.

Vamosi JC, Knight TM, Steets JA, Mazer SJ, Burd M, Ashman T (2006). Pollination decays in biodiversity hotspots. Proc Natl Acad Sci USA 103: 956-961.

Vekemans X, Hardy OJ (2004). New insights from fine-scale spatial genetic structure analyses in plant populations. Mol Ecol 13: 921-935.

Waser NM (1993). Population structure, optimal outbreeding, and assortative mating in angiosperms. In: Thornhill NW (ed). The Natural History of Inbreeding and Outbreeding: Theoretical and Empirical Perspectives. The University of Chicago Press: Chicago. pp 173-199.

Webb CJ (1998). The selection of pollen and seed dispersal in plants. Plant Species Biol 13: 57-67.

Wiens D, Renfree M, Wooller RO (1979). Pollen loads of honey possums (Tarsipes spenserae) and nonflying mammal pollination in southwestern Australia. Ann Missouri Botanic Garden 66: 830-838.

Wooller SJ, Wooller RD (2004). Seed viability in relation to pollinator availability in Banksia baxteri. Aust J Botany 52: 195-199.

Wright $S$ (1946). Isolation by distance under diverse systems of mating. Genetics 31: 39-59.

Wright S (1969). Evolution and the Genetics of Populations. Vol. 2, The Theory of Gene Frequencies. University of Chicago Press: Chicago.

Zawko G, Krauss SL, Dixon KW, Sivasithamparam K (2001). Conservation genetics of the rare and endangered Leucopogon obtectus (Ericaceae). Mol Ecol 10: 2389-2396. 